\title{
Attrition Among Families of Divorce: Patterns in an Outpatient Psychiatric Population
}

\author{
James Rembar \\ Jack Novick \\ Neil Kalter
}

ABSTRACT: The accelerated divorce rate has greatly increased the number of children of divorce. In addition, the children and families of divorce are proportionately overrepresented in populations seeking child guidance and psychiatric services. However, the patterns in the use of such services by these families has been unexamined. In our study we find no differences in the use of outpatient psychiatric services between families where both biological parents are present and families of divorce. A closer look at the divorced families reveals that recently divorced mother-headed families more frequently interrupt both the evaluation and treatment phases of clinic contact. Several clinical patterns are described which help explain the finding and it is suggested that the traditional child guidance model may not be the most suitable intervention modality in working with these families.

Statements on the accelerated divorce rate are now commonplace. The break-up of so many marriages has led to a new sociological classification-children of divorce-and their ranks increase by more than 1,000,000 a year with predictions of ever greater numbers in the future (Bane, 1979). Research efforts of just a few years ago

This article is reprinted with permission from the Journal of the Academy of Child Psychiatry, Vol. 21, 1982, pp. 409-413. James Rembar, PHD, is with the Department of Psychiatry, New York Hospital-Cornell Medical Center. Westchester Division, 27 Bloomingdale Road, White Plains, NY 10605. Jack Novick and Neil Kalter are with the University of Michigan. Reprints requests should be directed to Dr. Rembar. 
were infrequent, but there is now a burgeoning literature on the impact of divorce. Studies have focused on pre-divorce tensions, parental hostilities, loss of a parent, changing family roles, economic distress, visitation, and legal entanglements, among other topics (Cline \& Westman, 1971; Hetherington, Cox, \& Cox, 1976, 1977; Kelly \& Wallerstein, 1976; Tooley, 1976; Wallerstein \& Kelly, 1974, 1975, 1976; Westman, Cline, Swift, \& Kramer, 1970). Although controversy still exists about the nature, severity, and duration of the impact of divorce on children, it is now well documented that children of divorce are overrepresented in clinic populations. Studies from recent years report figures ranging from $27 \%$ to $33 \%$ for children of divorce (Kalter, 1977; Kalter \& Rembar, 1981; Morrison, 1974; Sugar, 1970).

Despite the accumulating clinical wisdom and research findings on the impact of divorce on children, and the reported associations between divorce and the seeking of child clinical services, the use of these services by families of divorce has not been examined as yet. Whether self-referred or referred by others such as schools, pediatricians, and courts, the parents and children of divorce apparently have a need for psychiatric services. Not only are they overrepresented in clinic populations, but it seems that these families present with specific needs and difficulties that are different from other families. Case study reports and anecdotal illustrations suggest that the fantasies and expectations of those seeking such services often bear the stamp of the divorce experience.

As with other families, the parents are the major decision makers at any point in the utilization of child guidance and psychiatric services. The initial expectations of these families, the extent to which they feel their needs are met, and the nature and duration of their contacts with mental health agencies are issues which remain unexplored. An examination of the patterns in the use and refusal of psychiatric services may begin to illuminate these questions and possibly serve to alert mental health practitioners to the special circumstances and needs of such families.

\section{METHOD}

This study was conducted at the Youth Service, Department of Psychiatry, University of Michigan Medical School. The overall sample was composed of the 1,188 cases assigned for outpatient evaluation in the calendar years 1975 and 1976. The records of all but 34 $(2.9 \%)$ were located, thus yielding a sample of 1,154 cases. 
Each case was coded for age, sex, and race of the child, current household income, marital status of the biological parents, current residence of the child, and whether a divorce had occurred in the past year. As noted in a previous publication (Novick, Benson \& Rembar, 1981), reliability was highly satisfactory. The child patients in the total sample range in age from infancy to 18 year; about $45 \%$ are 12 years and above; $40 \%$ are 6 to 11 years; and the remaining $15 \%$ are preschoolers. Males outnumber females by nearly 2 to 1 . The families are primarily of middle and lower socioeconomic status and $87 \%$ are white, $11 \%$ black, and $2 \%$ other.

The nature of the response to the outpatient contact was examined by determining whether there was an agreed-upon termination between family and agency or whether the family decided unilaterally to break off contact. The nonagreed terminations were categorized further according to the phase of clinic contact, thus generating five outcome categories:

1. Closed/not seen: Cases in which families were assigned for evaluation but failed to appear for any interview following the initial intake.

2. Incomplete evaluation: Cases which began the evaluation process but did not complete it.

3. Refused recommendation: Cases which completed the evaluation, including the final interpretive interview in which findings and recommendations are presented, but either overtly refused or simply did not appear for recommended outpatient treatment.

4. Unilateral treatment termination: Cases which complete intake and evaluation and enter outpatient treatment, but unilaterally withdraw from outpatient treatment against the advice of psychotherapist.

5. Agreed treatment termination: Outpatient treatment cases terminated by mutual agreement between therapist and patient/family.

The five categories accounted for 720 of the original 1,154 cases. Four-hundred thirteen cases $(36.5 \%)$ were referred elsewhere at the conclusion of the evaluation and were not followed beyond evaluation, 14 cases could not be categorized, and 7 others were still actively in treatment, after more than 2 years. Coding was done by advanced psychology graduate students and the initial reliability check revealed $90.8 \%$ exact agreement between pairs of coders, and a subsequent recheck yielded $100 \%$ agreement. 


\section{RESULTS}

\section{Demographic Variables}

The marital status of the biological parents in the full sample divide into the following percentages: $45.8 \%$ married to each other, $31.4 \%$ divorced, $8.6 \%$ separated, $8.5 \%$ never married, and $5.6 \%$ widowed. This demonstrates once again the high proportion of children of divorce in an outpatient psychiatric sample. When combined with the separated families a full two-fifths of the sample is represented. In comparing the married and divorced groups, the child's current residency status was also noted, since a child may be out of the home for other reasons such as adoption or institutional placement. We decided to restrict the married group to those living with one biological parent in an effort to eliminate the effects of other current residence factors which could confound the comparisons of primary interest.

In the demographic comparisons between the married and divorced groups, there are pronounced race and income differences. There is a much greater representation of black families among the divorced group $\left(\chi^{2}=20.3, d f=2, p \triangleleft 0.001\right)$. Blacks constitute $12.5 \%$ of the divorced group and only $3.5 \%$ of the married group. With income divided into five categories, a strongly linear pattern is revealed in which families of divorce have much lower levels of income $\left(\chi^{2}=13.5, d f=4, p \varangle 001\right)$. In particular, the proportion of divorced families receiving Aid to Dependent Children is more than 10 times greater than the proportion for married families $(29.1 \%$ to $2.5 \%)$. At the other end of the spectrum, income of $\$ 25,000$ or more, the proportions reverse as families of divorce have only one-third the representation of married families ( $4.0 \%$ to $12.6 \%$, respectively). These findings for race and income confirm patterns which have been found in other studies of nonclinic populations (Bane, 1979; Bloom, Asher, \& White, 1978; Click, 1979). In addition, there are slight differences with respect to age and sex which tend toward statistical significance.

\section{Service Utilization}

Turning to the patterns of contact with the outpatient clinic, there are no differences between the married and divorced groups in the use of psychiatric services reflected in either the overall comparison between agreed and nonagreed terminations or in the more specific five category code. However, in comparing families with a divorce 
in the past year to those divorced longer, pronounced differences emerge with respect to service utilization. The group divorced in the past year has a much lower agreed termination rate, only one of the 34 cases reaching an agreed termination (2.9\% compared to $16.6 \%$, Fisher exact probability $=0.03$ ). The more detailed analysis (see Table 1) across the five outcome categories is also highly significant $\left(\chi^{2}=12.04, d f=4, p=0.02\right)$.

Inspection of Table 1 reveals a pattern in which the recently divorced families more frequently interrupt an ongoing process. They are overrepresented among those who interrupt both evaluation and treatment and underrepresented among those who discontinue at the completion of the evaluation (refused recommendation) and as noted, those who reach an agreed termination. An intriguing parallel is suggested in which the recent marital disruption may be reflected in the nature of the termination of psychiatric services.

The finding above was investigated further in two ways. A previous study demonstrated an association between patterns of termination and time lag (Novick et al., 1981); thus it seemed possible that the differences found in the current study might be associated with differences in the length of time taken at any of the phases of clinic contact. Those divorced in the past year were compared to those divorced longer with respect to a series of discrete time spans. Statistical significance was examined with $t$ tests and no differences were

Table 1

Timing of Divorce and Outcome Categories

\begin{tabular}{|c|c|c|c|c|}
\hline \multirow[b]{2}{*}{ Outcome } & \multicolumn{2}{|c|}{$<$ One Year } & \multicolumn{2}{|c|}{$>$ One Year } \\
\hline & $\%$ & $N$ & $\%$ & $N$ \\
\hline Closed/not seen & 23.5 & 8 & 25.2 & 41 \\
\hline Incomplete evaluation & 26.5 & 9 & 17.2 & 28 \\
\hline Refused recommendation & 5.9 & 2 & 17.2 & 28 \\
\hline Unilateral termination & 41.2 & 14 & 23.9 & 39 \\
\hline Agreed termination & 2.9 & 1 & 16.6 & 27 \\
\hline Total & 100.0 & 34 & 100.1 & 163 \\
\hline
\end{tabular}


found, thus indicating that these two groups do not differ with regard to the average span of time for any of the phases of clinic contact.

Second, it seemed necessary to take into account the systematic differences in household structure between the two divorce groups. As would be expected, a much greater proportion of the recently divorced families are headed by the mother alone. Seventy-nine percent $(N=34)$ of the recently divorced families consists of singlemother households as compared to $54 \%(N=163)$ of the families divorced longer. It is possible that the former group is dealing not so much with the recent impact of the divorce itself, but with the stresses of single parenthood. In order to take household structure into account, the analysis of outcome categories and timing of divorce was redone for single-mother households only (see Table 2).

The proportions in Table 2 are nearly identical to those in Table 1 , thus demonstrating that the control for household structure does not alter the pattern of the initial finding. However, the $48 \%$ reduction of sample size for this analysis yields a somewhat less statistically significant result $(\chi=7.57, d f=4, p=0.11)$. Our results have isolated a subgroup within the total divorce sample which differs significantly in the use of psychiatric services for children - the group of divorced families headed by mother alone who have undergone a divorce within the past year.

Table 2

Timing of Divorce and Outcome Categories

\begin{tabular}{|c|c|c|c|c|}
\hline \multirow[b]{2}{*}{ Outcome } & \multicolumn{2}{|c|}{$<$ One Year } & \multicolumn{2}{|c|}{$>$ One Year } \\
\hline & $\%$ & $N$ & $\%$ & $N$ \\
\hline Closed/not seen & 22.2 & 6 & 23.9 & 21 \\
\hline Incomplete evaluation & 25.9 & 7 & 14.8 & 13 \\
\hline Refused recommendation & 3.7 & 1 & 14.8 & 13 \\
\hline Unilateral termination & 44.4 & 12 & 31.8 & 28 \\
\hline Agreed termination & 3.7 & 1 & 14.8 & 13 \\
\hline Total & 99.9 & 27 & 100.1 & 88 \\
\hline
\end{tabular}


James Rembar, Jack Novick and Neil Kalter

\section{CONCLUSIONS AND DISCUSSION}

In summary, the families of divorce constitute a substantial portion $(31.4 \%)$ of all families contacting our outpatient clinic. Two major demographic differences characterize these families when compared to those families with both biological parents present. They have much lower income and a much higher proportion of black families, findings which have been reported in previous studies. The comparisons between the divorced and married families revealed no significant differences in the pattern of utilization of outpatient psychiatric services. However, an analysis within the divorce sample, comparing families divorced in the past year to those divorced longer, reveals that the former group has a significantly lower agreed termination rate and a significantly different pattern of service utilization.

Further statistical controls underline the finding that recently divorced, single-mother families constitute a distinct subsample of the total divorced group in relation to the use of psychiatric services for children and adolescents. Mother-headed families having undergone a recent divorce constitute a population at risk, as they break off clinic contact at a much higher rate than other divorce or nondivorce groups. The divorce literature has paid little attention as yet to the particular effects of recency and single parenthood on the divorced mothers who seek psychiatric help for their children. The statistical findings of this study validate our clinical experience in the treatment and supervision of such cases. Divorce is traumatic for all the mothers in our clinic sample across the broad range of attendant circumstances, causes, and sequelae. In addition to the evident economic disruption and changes in family roles, we have found that the more recent the trauma the more vulnerable these mothers are to being overwhelmed by powerful narcissistic, libidinal, and aggressive needs. The intimate nature of the usual parent guidance approach often intensifies these needs. It has been our experience, as confirmed by the statistical results of this study, that these mothers are at risk and will tend to break off contact unless treated with special care and understanding. We have been able to note several prominent patterns in work with recently divorced, single mothers, which threaten and usually interrupt the continuation of clinic contact. 


\section{Patterns of Adverse Reactions}

Passive to Active Reversal of Trauma. This is a frequent reaction to any trauma and these mothers will often "divorce" the parentworker leaving the professional with the feelings of helplessness, failure, and rage. This pattern is also clearly seen in the statistical results (see Table1) where, as noted, these mothers interrupt an ongoing process leaving the worker in the midst of evaluation or treatment. Thus the recent trauma of being the victim of a divorce is repeated with the worker now put in the passive position of being rejected and abandoned by the mother.

Negative Therapeutic Motivation. In a recent article (Novick, 1980), it was noted that a parent and child may create a treatment failure in order to externalize and locate the mother's failure outside the mother-child unit. The professional becomes the failure and the illusion of goodness and omnipotence is restored to the mother-child dyad. All the divorced families are plagued by doubts, to a greater or lesser extent, about the possible negative effects of the divorce on the children. In treatment this may take the form of "negative therapeutic motivation" in which help is sought in order to make it fail and thus externalize the experience of failure

Eroticized Transference. The loss through divorce of a marital partner is experienced as a sexual rejection by many, reawakening previous rejections and leaving the ex-spouse vulnerable to intense frustrated needs and sensitive to further rejection. In parent guidance, the custodial mother often needs to experience the relationship in sexual terms in order to prove that she is still sexually attractive. Attempts by the worker to set therapeutic limits can be experienced as a further rebuff. Unconscious eroticized transference reactions of a homo- or heterosexual orientation can become very intense and may threaten to break into consciousness. Treatment is then interrupted either as a flight from these feelings, or in response to the countertransference insensitivity of the worker.

Regressed Transference. The recently divorced mother may not only feel rejected but also abandoned and helpless. This often revives her own wishes for dependence on a powerful caretaker/mother. The relationship with the professional cannot satisfy these wishes, and disappointment, rage, and abrupt termination all too frequently follow.

Displacement of Battle with the Ex-Husband. The continuing battle with the ex-husband may be displaced onto the worker and a "custody" battle with the professional over possession of the child 
may occur. These mothers may find many of the traits of their ex-husband in their workers and a common fear is that the clinic will find the mothers to blame and take their child away.

These patterns are not mutually exclusive, exhaustive or unique to our sample. However, the recent experience of a divorce by a single mother often makes the special difficulties described clearly evident and at times seem of unmanageable proportions. Perhaps the variety of reactions described above could be best dealt with not only by those alert to the special needs of these mothers but also in a context other than individual work, such as parent support groups.

Our data indicate that many children of recently divorced single mothers are not receiving needed psychiatric services. And this underutilization exists even for youngsters whose mothers went so far as to seek a child psychiatric evaluation. Similar conflicts to ones presented here may well inhibit many other such mothers from seriously considering child guidance and psychiatric services.

We would suggest that this problem may be largely due to our own insensitivity to the special needs of this group of mothers. An awareness of the clinical issues at play, and perhaps the development of intervention procedures more suited to the needs of recently divorced mothers, may increase the effectiveness of professional help for these families.

\section{REFERENCES}

Bane, M.J. Marital disruption and the lives of children. In C. Levinger \& O.C. Moles (Eds.), Divorce an separation. New York: Basic Books, 1979.

Bloom, B.L., Asher, S.J., \& White, S.W. Marital disruption as a stressor: A review and analysis. Psychological Bulletin, 1978, 85, 867-894.

Cline, D.W. \& Westman, J.C. The impact of divorce on the family. Child Psychiatry and Human Development, 1971, 2, 78-83.

Glick, P.C. Children of divoced parents in demographic perspectict Journal of Social Issues, 1979, 35(4), 170-182.

Hetherington, E.M., Cox, M., \& Cox, R. The aftermath of divorce. In J.H. Stevens, Jr, \& M. Matthews (Eds.), Mother-child, father-child relations. Washington, DC: National Association for the Eduction of Young Children, 1977.

Kalter, N. Children of divorce in an outpatient psychiatric population. American Journal of Orthopsychiatry, 1977, 47, 40-51.

Kalter, N. \& Rembar, J. The significance of a child's age at the time of parental divorce. American Journal of Orthopsychiatry, 1981, 51, 85-100.

Kelly, J.B. \& Wallerstein, J.S. The effects of parental divorce: Experiences of the child in early latency. American Journal of Orthopsychiatry, 1976, 46, 20-32.

Morrison, J.R. Parental divorce as a factor in childhood psychiatric illness. Comprehensive Psychiatry, 1974, 15, 95-102. 
INTERNATIONAL JOURNAL OF FAMILY THERAPY

Novick, J. Negative therapeutic motivation and negative therapeutic alliance. The Pshcyoanalytic Study of the Child, 1980, 35, 299-320.

Novick, J., Benson, R., \& Rembar, J. Patterns of termination in an outpatient clinic for children and adolescents: I. Agreed termination and nonagreed termination. Journal of the American Academy of Child Psychiatry, 1981, 20, 834-844

Sugar, M. Children of divorce. Pediatrics, 1970, 46, 588-595.

Tooley, K. Antisocial behavior and social alienation post divorce: The "man or the house" and his mother. American Journal of Orthopsychiatry, 1976, 46, 33-42.

Wallerstein, J.S. \& Kelly, J.B. The effects of parental divorce: The adolescent experience. In E.). Anthony \& C. Koupernik (Ed5.), The child in his family (Vol. 3). New York: John Wiley \& Sons, 1974.

Wallerstein, J.S. \& Kelly, J.B. The effects of parental divorce: Experience of the preschool child. Journal of the American Academy of Child Psychiatry, 1975, 14, 600-616.

Wallerstein, J.S. \& Kelly, J.B. The effects of parental divorce: Experience of the child in later latency. American Journal of Orthopsychiatry, 1976, 46, 256-269.

Westman, J.C., Cline, D.W., Swift, W.J., \& Kramer, D.A. Role of child psychiatry in divorce. Archives of Ceneral Psychiatry, 1970, 23, 416-420. 